\section{Autonomic dysfunction in Hodgkin and non-Hodgkin lymphoma. A paraneoplastic syndrome?}

\author{
Franca Bilora, ${ }^{1}$ Francesco Veronese, ${ }^{1}$ \\ Alice Zancan, ${ }^{1}$ Michela Biasiolo, ${ }^{1}$ \\ Fabio Pomerri, ${ }^{2}$ Pier Carlo Muzzio ${ }^{2}$ \\ 12nd Internal Medicine Clinic University \\ of Padua and IRCSS-IOV, Padua, Italy; \\ 2Department of Medical-Diagnostic \\ Sciences and Special Therapies, \\ University of Padua and IRCSS-IOV, \\ Padua, Italy
}

\begin{abstract}
We wanted to determine whether autonomic dysfunction in patients with lymphoma is related to chemotherapy or represent a paraneoplastic syndrome. 40 patients with current or cured Hodgkin or non-Hodgkin lymphoma and 40 healthy controls, matched for age, gender, hypertension and diabetes mellitus underwent autonomic evaluation (Deep Breath, Valsalva Maneuver, Hand Grip, Lying to Standing, Tilt Test). Current patients also suffering from diabetes or hypertension, or still on chemotherapy revealed autonomic changes, while cured or healthy subjects did not. Autonomic dysfunction in lymphoma is a transient manifestation of a paraneoplastic syndrome.
\end{abstract}

\section{Introduction}

There is some controversy regarding the association between autonomic dysfunction and Hodgkin disease. Some papers report acute dysautonomia involving the parasympathetic and sympathetic system, like a paraneoplastic syndrome, in Hodgkin lymphoma ${ }^{1-4}$ and others describe improvements after the treatment of the disease. ${ }^{5}$ Some studies suggest that such autonomic changes are related to the malignant disease,${ }^{6}$ but others claim that they are the consequence of chemotherapy. ${ }^{7,8}$

Given these conflicting findings, we tried to verify whether lymphoma per se or chemotherapy for this disease genuinely influence the autonomic system. We considered two groups of patients with lymphoma: the first one was formed by subjects who had been cured, while the other one was constituted by cases still receiving treatment. These two groups were matched with a control group of healthy subjects. All individuals underwent to the classic autonomic tests.

\section{Materials and Methods}

In a period of over one year, we studied 40 cases (M 20; F 20; mean age 58.7 \pm 7.3 ), 18 of them of non-Hodgkin (NH) lymphoma and 22 of Hodgkin $(\mathrm{H})$ lymphoma, all attending our outpatients clinic for regular follow-up and/or treatment. All the cured subjects had received both chemotherapy (CT) and external beam radiotherapy (RT), the latest dose having been administered almost a year previously. The current patients were still receiving combined CT (including toxic agents such as vinca alkaloids) and/or RT based on international protocols. The control group was of 40 subjects (M 20; F 20; mean age 59.5 \pm 6.7 ) (Table 1).

All subjects underwent to the autonomic evaluation.

\section{Autonomic evaluation}

Subjects underwent cardiovascular autonomic nerve function tests, ${ }^{9}$ in the following order: Deep Breathing Test, Valsalva Test, Isometric Hand Grip Test, Laying to Standing Test and Tilt test. In the Deep Breathing Test, a test of vagal heart rate control, ${ }^{9}$ the duration of the expiratory and inspiratory breaths was 5 seconds each for a total of 40 seconds (4 respiratory cycles). The ratio of the longest to the shortest respiratory rate (RR) intervals was determined from the ECG for each respiratory cycle, and the mean of the four ratios was taken as the expiratory/inspiratory (E/I) ratio.

In the Valsalva Test, which measures both parasympathetic and sympathetic functions, subjects blew into a manometer, maintaining an intrathoracic pressure of $40 \mathrm{mmHg}$ for 15 seconds. The ratio between the shortest RR interval during the expiratory effort and the longest RR interval during the 20 seconds afterwards (Valsalva ratio) was calculated.

In the Isometric Hand Grip Test, subjects squeezed a dynamometer in their dominant hand for 3 minutes using a force corresponding to $30 \%$ of their maximal squeezing force. Heart rate and blood pressure were measured at rest, before and after gripping the dynamometer.

In the Laying to Standing Test, subjects suddenly stood up after resting quietly in a supine position for 5 minutes. Heart rate and blood pressure were measured at rest and then 1,3 , 5 and 7 minutes after standing up.

In the Tilt Test, subjects laid supine on an electric tilt table. A restraining strap, applying a negligible pressure to the surface of the body put across the upper abdomen, secured the patients to the tilt table during the upright tilt. Humeral blood pressure and electrocardiograms were recorded continuously throughout the test, which lasted 30 minutes and was judged to be positive only in the case of symptoms fully reproducing the patient's original
Correspondence: Franca Bilora, Clinica Medica II, Università di Padova, via Giustiniani 2, 35128 Padova - Italy.

E-mail: franca.bilora@sanita.padova.it

Key words: autonomic dysfunction, lymphoma.

Received for publication: 6 September.

Revision received: 11 November.

Accepted for publication: 20 November 2010.

This work is licensed under a Creative Commons Attribution 3.0 License (by-nc 3.0)

() Copyright F. Bilora et al., 2010

Licensee PAGEPress, Italy

Hematology Reports 2010; 2:e8

doi:10.4081/hr.2010.e8

pre-syncopal or syncopal symptoms accompanied by arterial hypotension, bradycardia or both. ${ }^{10,11}$

\section{Statistical analysis}

Autonomic test results were compared using Student's two tailed t-test for matched data. Statistical significance was set at $\mathrm{P}<0.05$.

\section{Results}

Table 1 shows the general characteristics of cases and controls. Table 2 summarizes the results of the autonomic tests in current patients and cured subjects: the latter had no autonomic dysfunction, whereas current patients had altered Deep Breathing Test results and Valsalva ratios. We also evaluated current cases and cured cases versus healthy subjects and we found that the autonomic evaluation was altered only in current cases, while cured patients did not differ from healthy (Tables 3, 4).

\section{Discussion}

Autonomic dysfunction is documented in cases of lymphoma, ${ }^{5}$ but it is important to clarify whether this is a paraneoplastic manifestation or a consequence of chemotherapy $y^{7,12}$ because, in the first hypothesis, chemotherapy can cure the alteration, while in the second one it may exacerbate the dysfunction, with all the well-known consequences. In fact, autonomic impairment is responsible for a higher mortality rate due to cardiovascular disease, such as sudden death resulting from cardiac arrhythmia. ${ }^{1}$ Our study shows that dysautonomia in lymphoma is a direct consequence of the disease and that cured patients show no more signs of this alteration; so they return to 
Table 1. General characteristics of Hodgkin and non-Hodgkin subjects and controls.

\begin{tabular}{lcc} 
& Hodgkin and non Hodgking subjects & Controls \\
Age (years) & $58.7 \pm 7.3$ & $59.5 \pm 6.7$ \\
Gender (\%males) & $50 \%$ & $50 \%$ \\
\hline Diabetes mellitus & $1.6 \%$ & $2.4 \%$ \\
Hypertension & $2.4 \%$ & $3.2 \%$ \\
\hline
\end{tabular}

Table 2. Results of autonomic tests in the study groups (Current vs. Cured patients).

\begin{tabular}{lccc} 
Test & Parameter & Current pts $\left(\mathbf{n}^{\circ} \mathbf{2 2}\right)$ & Cured pts $\left(\mathbf{n}^{\circ} \mathbf{4} \mathbf{0}\right)$ \\
Deep breathing & E/I ratio & $1.1 \pm 0.03$ & $1.4 \pm 0.04^{*}$ \\
Valsalva maneuver & Valsalva ratio & $1.3 \pm 0.1$ & $1.9 \pm 0.1^{*}$ \\
\hline Hand grip test & $\begin{array}{c}\text { Diastolic blood pressure } \\
\text { increase in mHg }\end{array}$ & $19.1 \pm 3.1$ & $23.3 \pm 3.1$ \\
Laying to standing test & $\begin{array}{c}\text { Systolic blood pressure } \\
\text { decrease in mmHg }\end{array}$ & $-5.2 \pm 6.2$ & $-3.4 \pm 4.5$ \\
\hline Tilt test & RR intervals & $1.08 \pm 0.01$ & $1.2 \pm 0.03$ \\
\hline${ }^{*}<0.05$ & & &
\end{tabular}

Table 3. Results of autonomic tests in the study groups (Current patients vs Healthy subjects).

\begin{tabular}{lccc} 
Test & Parameter & Current pts (n 22) & Cured pts $\left(\mathbf{n}^{\circ} \mathbf{1 8}\right)$ \\
Deep breathing & E/I ratio & $1.1 \pm 0.03$ & $1.42 \pm 0.02^{*}$ \\
Valsalva maneuver & Valsalva ratio & $1.3 \pm 0.1$ & $1.86 \pm 0.3^{*}$ \\
\hline Hand grip test & $\begin{array}{c}\text { Diastolic blood pressure } \\
\text { increase in mmHg } \\
\text { Systolic blood pressure } \\
\text { decrease in mming to standing test }\end{array}$ & $19.1 \pm 3.1$ & $20.4 \pm 4.7$ \\
\hline Tilt test & RR intervals & $-5.2 \pm 6.2$ & $-5.5 \pm 4.6$ \\
\hline P $<0.05$ & & $1.08 \pm 0.01$ & $1.12 \pm 0.01$ \\
\hline
\end{tabular}

Table 4. Results of autonomic tests in the study group (Cured vs. Healthy subjects).

\begin{tabular}{lccc}
\hline Test & Parameter & Cured pts $\left(\mathbf{n}^{\circ} \mathbf{1 8}\right)$ & Healthy $\left(\mathbf{n}^{\circ} \mathbf{4 0}\right)$ \\
Deep breathing & E/I ratio & $1.4 \pm 0.04$ & $1.42 \pm 0.02$ \\
Valsalva maneuver & Valsalva ratio & $1.9 \pm 0.1$ & $1.86 \pm 0.3$ \\
\hline Hand grip test & $\begin{array}{c}\text { Diastolic blood pressure } \\
\text { increase in mmHg }\end{array}$ & $23.3 \pm 3.1$ & $20.4 \pm 4.7$ \\
Laying to standing test & $\begin{array}{c}\text { Systolic blood pressure } \\
\text { decrease in mmHg }\end{array}$ & $-3.4 \pm 4.5$ & $-5.5 \pm 4.6$ \\
\hline Tilt test & RR intervals & $1.2 \pm 0.03$ & $-5.5 \pm 4.6$ \\
\hline
\end{tabular}

a normal state like control subjects. This result is confirmed also by the fact that our subjects, even if treated with vincristine, did not manifested any neuropathy like Pal reported. ${ }^{13}$ However it could be possible that these changes depend on other factors different from chemotherapy. The results confirm that autonomic changes in patients with lymphoma may represent a paraneoplastic disease.

\section{References}

1. Crespo M, Correia L, Ferreira F, DuclaSoares JL. Acute dysautonomia associated to Hodgkin lymphoma. Acta Med Port 2002;15:153-4.

2. Goldsmith DJ, Farmer CK. Autonomic neuropathy with B-cell lymphoma. JR SocMed
2000;93:377-8.

3. Lavi S, Aharon-Peretz J, Haim N, et al. Unusual cause of partially reversible severe cardiovascular autonomic failure. Am J Med Sci 2003;326:159-63.

4. Martin R, Delgado JM, Moltò JM, et al. J. Cardiovascular reflexes in patients with malignant disease. Ital J Neurol Sci 1992; 13:125-9.

5.Turner ML, Boland OM, Parker AC, Ewing DJ. Subclinical autonomic dysfunction in patients with Hodgkin's disease and nonHodgkin lymphoma. Br J Haematol 1993 ;84:623-6.

6. Adams MJ, Lipsitz SR, Colan SD, et al. Cardiovascular status in long term survivors of Hodgkin's disease treated with chest radiotherapy. J Clin Oncol. 2004;22: 3139-48.

7. Pal PK. Clinical and electrophysiological studies in vincristine-induced neuropathy. Electromyogr Clin Neurophysiol. 1999;39: 323-30.

8. Goldsmith DJ, Farmer CK. Autonomic neuropathy with B-cell lymphoma. JR SocMed 2000;93:377-8.

9. Bannister M, Mathias CJ, eds , 1998. Autonomic failure: a textbook of Clinical Disorders of the Autonomic Nervous System. 3rd ed. Oxford, UK: Oxford University Press.

10. Task Force of the European Society of cardiology and North American Society of Pacing and Electrophysiology. Heart rate variability: standards of measurements, physiological interpretation, and clinical use. Circulation 1996;93:1043-1065.

11. Sutton R, Bloomfield D. Indications, methodology, and classification of results of tilt table testing. Am J Cardiol 1999,84: 10-9.

12. Gold von Simson G, Rutkowski M, Berlin D, Axelrod FB. Pacemaker in patients with familial dysautonomia - a review of experience with 20 patients. Clin Auton Res 2005; 15:6-9.

13. Pal PK. Clinical and electrophysiological studies in vincristine induced neuropathy. Electromyogr Clin Neurophysiol 1999;39: 323-30. 